(c) American Dairy Science Association, 2002.

\title{
Efficacy of Systemic Ceftiofur as a Therapy for Severe Clinical Mastitis in Dairy Cattle
}

\author{
R. J. Erskine, P. C. Bartlett, J. L. VanLente, and C. R. Phipps \\ Department of Large Animal Clinical Sciences \\ College of Veterinary Medicine \\ Michigan State University \\ East Lansing, Michigan 48824
}

\begin{abstract}
The objectives of this study were to determine the efficacy of intramuscular administration of ceftiofur to reduce the incidence of case-related death and culling following severe clinical mastitis in lactating dairy cattle. A total of 104 cows with severe clinical mastitis (systemic signs) were enrolled in the study and randomly assigned to one of two treatment groups. Immediately after detection of the case, one group was administered $2.2 \mathrm{mg} / \mathrm{kg}$ of ceftiofur intramuscularly, and the dose repeated at 24-h intervals for a total of five doses. The second group of cows did not receive systemic antibacterial therapy. Additionally, all cows in both treatment groups received intramammary pirlimycin (Pirsue $^{\circledR}$ ) in the affected quarter every $24 \mathrm{~h}$ for a total of up to three doses. Also at the onset of the case, all cows on the trial were administered a supportive therapeutic regimen of fluids and anti-inflammatory agents that varied from farm to farm, but was standard within each herd at the discretion of the herd manager and veterinarian. Of all cases 14/104 (13.5\%) resulted in a lost cow (died or culled). The proportion of cases that resulted in a lost cow and were treated with ceftiofur $(4 / 51 ; 7.8 \%)$ did not statistically differ from cows that were not treated with ceftiofur $(10 / 53 ; 18.9 \%)$. However, the proportion of cases that resulted in lost cows was higher for those cases that yielded a coliform organism on culture $(14 / 56 ; 25.0 \%)$ than cases that did not yield coliforms $(0 / 48 ; 0.0 \% ; P<0.001)$. Thus, among coliform cases, cows that were not treated with ceftiofur were more likely to be culled or die $(10 / 27,37.0 \% ; P<0.05)$ than cows treated with ceftiofur $(4 / 29,13.8 \%)$. We conclude that intramuscular administration of ceftiofur did not affect the outcome of severe clinical mastitis when all etiologic agents are included in the analysis. However, for severe clinical mastitis cases caused by coli-
\end{abstract}

Received October 17, 2001

Accepted March 11, 2002.

Corresponding author: R. J. Erskine; e-mail: erskine@cvm. msu.edu. form organisms, ceftiofur therapy reduced the proportion of cases that resulted in cow death or culling. This benefit may be realized because of the amelioration of bacteremic-related pathogenesis.

(Key Words: clinical mastitis, ceftiofur, therapy)

\section{INTRODUCTION}

Although the clinical benefits of antibacterial therapy administered by intramammary infusion for severe coliform mastitis are questionable (Erskine, 2000), systemic antibacterial therapy may favorably influence the outcome of this disease (Shpigel et al., 1997; Morin et al., 1998a). The benefit of systemic administration of an antibacterial may be gained by the amelioration of deleterious effects of bacteremia, which has been reported to occur in 32\% (Cebra et al., 1996) and 45\% of severe coliform mastitis cases (Wenz et al., 1998). Ceftiofur, when administered intramuscularly, does not attain effective concentrations in the mammary gland (Owens et al., 1990; Erskine et al., 1995). However, ceftiofur may be appropriate as a therapy to reduce the clinical effects of bacteremia as concentrations can be maintained in plasma that are well above the minimum inhibitory concentrations for a wide range of bacteria, including coliforms. Additionally, this drug is approved for use in lactating dairy cattle, and has no withholding period for milk or meat following the labeled dose of up to $2.2 \mathrm{mg} / \mathrm{kg}$ daily for $5 \mathrm{~d}$. The objectives of this study were to determine the efficacy of intramuscular administration of ceftiofur to reduce the incidence of case-related death and culling from severe clinical mastitis in lactating dairy cattle.

\section{METHODS}

\section{Herd Selection}

We selected six Michigan dairy farms to participate in the study. The time of participation for each herd varied from 3 to 15 mo. Herds were selected if drycow therapy and udder hygiene during milking were practiced, contagious mastitis was effectively con- 
trolled, and a sanitary environment for adult cattle was maintained. Herd size ranged from 120 to 700 milking cows, and all herds had the ability to record daily milk weights for each cow.

\section{Selection of Cows for Treatment (Case Definition)}

Lactating cows that were determined to have severe clinical mastitis were enrolled in the study. Severe clinical mastitis was defined as cows with a hard, swollen quarter of the mammary gland, abnormal milk, and at least two of the following clinical signs suggestive of systemic involvement: 1) rectal temperature $\geq 39.5^{\circ} \mathrm{C}$ $\left(\geq 103^{\circ} \mathrm{F}\right.$ as observed on farm), 2) anorexia, 3) marked depression, 4) decreased milk production, or 5) shock (increased heart rate, tenting of eyelids, shivering, slow capillary refill time). This assessment was performed for all cases by farm personnel that were trained by the investigators. Cows were excluded from the study if 1 ) they were previously enrolled in the study, 2) there was teat trauma of the affected quarter, 3) there were two or more affected quarters with acute inflammation at the time of clinical presentation, 4) concurrent diseases such as displaced abomasum, hypocalcemia, severe lameness, rumen acidosis, pneumonia, or recumbency were present before the onset of clinical mastitis, and 5) there was a history of chronic mastitis or intramammary antimicrobial therapy in the affected quarter $30 \mathrm{~d}$ before enrollment.

\section{Dosage and Treatment Administration}

Herd personnel assigned cows to one of two treatment groups. Two blocks, parity 1 to 2 and parity $3+$, were used for each herd. Before the initiation of the study, the two treatments were randomly assigned in a pairwise fashion to each of the two parity blocks so that the number of subjects in each block receiving each treatment were approximately balanced. As cows meeting the enrollment criteria were presented, they were assigned to the next treatment indicated in the appropriate parity block. Immediately after detection of the case, one group of cows was administered $2.2 \mathrm{mg} / \mathrm{kg}$ of ceftiofur intramuscularly, and the ceftiofur dose was repeated at 24-h intervals for a total of five doses. The maximum volume of drug administered at any one injection site was $12 \mathrm{~mL}$. Before administration of the ceftiofur, the cow was taped to ascertain BW. The second group of cows did not receive any systemic antibacterials. Additionally, to encompass the possibility of Gram-positive agents as the cause of the clinical mastitis case, all cows in both treatment groups received intramammary pirlimycin (Pirsue ${ }^{\circledR}$ ) in the affected quarter every $24 \mathrm{~h}$ for a total of up to three doses. The number of pirlimycin doses varied between herds, but was consistent within a herd. Because of pirlimycin treatment, milk from treated cows was discarded for $36 \mathrm{~h}$ after treatment, and cows that were to be culled were not sent to slaughter for $28 \mathrm{~d}$.

Also at the onset of the case, all cows on the trial were administered a supportive therapeutic regimen that typically included: 1) $7.0 \%$ sodium chloride (hypersaline) administered intravenously 2) $500 \mathrm{~mL}$ of calcium borogluconate (10.7 $\mathrm{g}$ of calcium) administered subcutaneously, 3) $20 \mathrm{mg}$ of isoflupredone acetate administered intramuscularly or $1.1 \mathrm{mg} / \mathrm{kg}$ of flunixin meglumine administered intravenously as anti-inflammatory agents, 4) oral fluids, and 5) other drugs or vitamins as indicated by the herd manager and veterinarian. The supportive therapeutic regimen varied from farm to farm at the discretion of the herd manager and veterinarian, but did not include any additional antibacterials. Each herd recorded a standard protocol for supportive therapy at the beginning of the trial. This protocol was maintained throughout the trial and did not differ between treatment groups within a herd. The herd owner/manager administered and recorded all treatments.

The initial antimicrobial and supportive therapy was administered as outlined in the herd protocol. After 48 $\mathrm{h}$, in the opinion of the herd manager/veterinarian, if a mastitis case was not responding to the protocol regimen, additional antibacterial therapy was administered, and the cow was considered to be a treatment failure.

\section{Milk Sample Collection}

Farm personnel collected aseptic milk samples from the affected quarter at the time of detection before any treatment was administered. A total volume of approximately $10 \mathrm{~mL}$ was collected and frozen on farm. The samples were stored in a freezer until collected by the investigators. The maximum on-farm storage period was $3 \mathrm{wk}$.

\section{Bacterial Culture of Milk}

Milk samples were cultured for the presence of bacteria in our mastitis research laboratory at Michigan State University. Initial isolation was performed on 5\% sheep blood agar plates and MacConkey's agar under aerobic conditions at $37^{\circ} \mathrm{C}$ for $48 \mathrm{~h}$. Isolated bacteria were identified as described in the Laboratory and Field Handbook on Bovine Mastitis (NMC, 1999).

\section{Outcome Determination}

Categorical outcome variables included the incidence of treatment failures and survival in the herd (culling 
Table 1. Herd enrollment of severe clinical mastitis cases for six Michigan dairy herds.

\begin{tabular}{|c|c|c|c|c|c|c|c|c|}
\hline Herd & No. Milking cows & $\begin{array}{l}\text { Total cows enrolled } \\
\text { with severe mastitis }\end{array}$ & Escherichia coli & Klebsiella sp. & Strep sp. & Staph sp. & Other pathogen & No isolation \\
\hline $\mathrm{A}$ & 750 & 20 & 11 & 0 & 6 & 1 & 0 & 2 \\
\hline B & 150 & 7 & 2 & 0 & 3 & 2 & 0 & 0 \\
\hline $\mathrm{D}$ & 300 & 23 & 14 & 0 & 0 & 1 & 1 & 7 \\
\hline $\mathrm{E}$ & 700 & 42 & 13 & 7 & 4 & 3 & 3 & 12 \\
\hline $\mathrm{F}$ & 450 & 9 & 3 & 4 & 0 & 2 & 0 & 0 \\
\hline Total & 2,750 & 104 & 44 & 12 & 14 & 9 & 4 & 21 \\
\hline
\end{tabular}

and death) within $30 \mathrm{~d}$ after the clinical case onset. These data were recorded and maintained on a written system provided by the investigators.

\section{Statistical Analysis}

Treatments were randomly assigned to each of two parity blocks within each herd. The young parity group contained the first and second lactation cows, and the older parity group contained cows in their third or greater lactation. Categorical (dichotomous) outcome variables were evaluated with the StatCalc procedure of EpiInfo6; the Maentel-Hanszel analysis was used to calculate the chi-square statistic. A Fisher's Exact Test was used for comparisons that lacked enough cases to determine expected values. Treatment effects were considered statistically significant for a particular study output if the treatment $P$ value for the above analysis was $<0.05$.

\section{RESULTS}

A total of 104 cows was enrolled in the study; total enrollment by herd and bacteriologic etiology are presented in Table 1. Coliform organisms (Escherichia coli

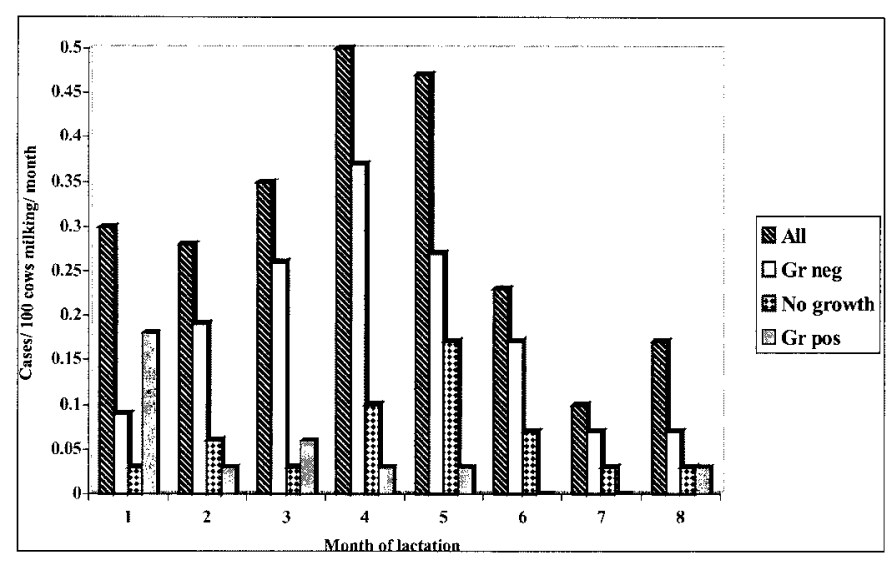

Figure 1. Incidence of severe clinical mastitis in six Michigan dairies by month of lactation. Gr neg = Gram negative; Gr pos = Gram positive. and Klebsiella sp.) were the predominant agents (56/ $104 ; 53.8 \%$ ), although no organism was isolated for 21/ $104(20.2 \%)$ of the cases (Table 1$)$. The incidence of recorded severe mastitis in the six herds ranged from 0.06 to 0.64 cases $/ 100$ cows milking/month, with a mean of 0.31 cases $/ 100$ cows milking per month. The number of cases of severe mastitis that occurred by month of lactation is presented in Figure 1. The fourth and fifth month of lactation (between 91 and $150 \mathrm{~d}$ in milk) had the greatest frequency of total cases and cases identified as being caused by Gram-negative organisms. Approximately $45 \%$ of the cases had a rectal temperature below $39.5^{\circ} \mathrm{C}\left(103^{\circ} \mathrm{F}\right)$ at the time of presentation (Figure 2).

Twenty of $104(19.2 \%)$ cases required additional therapeutic intervention $48 \mathrm{~h}$ after case onset, of which 6/ $104(5.8 \%)$ continued to milk and 14/104 (13.5\%) were nonsurvivors (Table 2). The proportion of all treatment failures (milking and nonsurvivor cows) was 8/51 (15.7\%) for the cows treated with ceftiofur, and did not statistically differ $(12 / 53 ; 22.6 \%)$ from untreated cows (Table 2). However, the proportion of all treatment failures was higher for those cases that yielded a coliform organism on culture $(18 / 56,32.1 \% ; P<0.001)$ than cases that did not yield coliforms $(2 / 48,4.2 \%$; Table 2$)$. Likewise, the proportion of cases that resulted in nonsurvival was higher for those cases that yielded a coliform

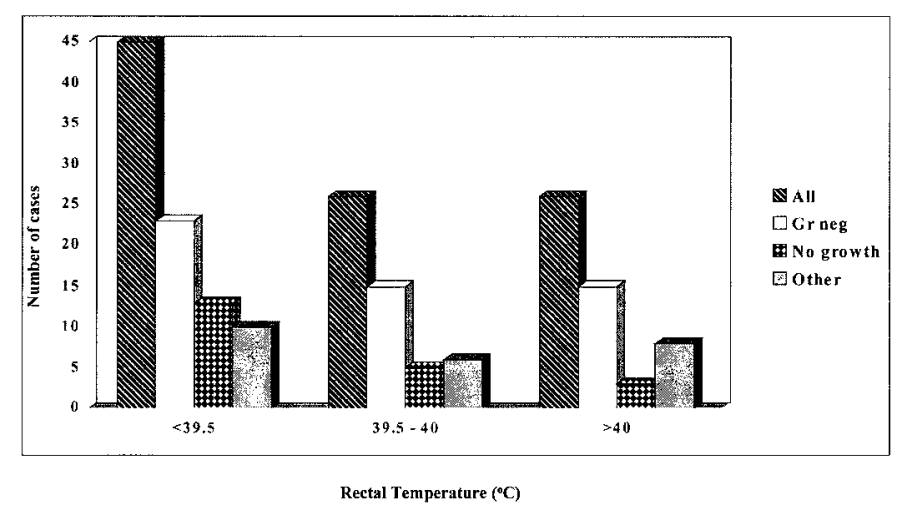

Figure 2. Rectal temperatures at clinical onset of severe clinical mastitis. Gr neg = Gram negative. 
Table 2. Clinical outcome of severe mastitis.

\begin{tabular}{|c|c|c|c|c|c|c|c|}
\hline Clinical outcome & Total cows & Escherichia coli & Klebsiella & Strep sp. & Staph sp. & Other pathogen & No isolation \\
\hline \multicolumn{8}{|l|}{ Ceftiofur } \\
\hline Therapy success & 43 & 18 & 4 & 7 & 4 & 2 & 8 \\
\hline Failure: milking ${ }^{1}$ & 4 & 1 & 2 & 0 & 1 & 0 & 0 \\
\hline Failure: nonsurvival ${ }^{2}$ & 4 & 2 & 2 & 0 & 0 & 0 & 0 \\
\hline Total & 51 & $2 \overline{1}$ & 8 & 7 & 5 & 2 & 8 \\
\hline \multicolumn{8}{|l|}{ Control } \\
\hline Therapy success & 41 & 15 & 1 & 7 & 3 & 2 & 13 \\
\hline Failure: milking ${ }^{1}$ & 2 & 1 & 0 & 0 & 1 & 0 & 0 \\
\hline Failure: nonsurvival ${ }^{2}$ & 10 & 7 & 3 & 0 & 0 & 0 & 0 \\
\hline Total & 53 & 23 & 4 & 7 & 4 & 2 & 13 \\
\hline
\end{tabular}

${ }^{1}$ Additional systemic antibacterials administered after $48 \mathrm{~h}$ on protocol; cows remained in milking herd.

${ }^{2}$ Additional systemic antibacterials administered after $48 \mathrm{~h}$ on protocol; cows were culled or died within $28 \mathrm{~d}$ after clinical case onset. For ceftiofur-treated cows two died, two culled; for controls: five died, five culled. For cases with coliform isolations, difference between ceftiofurtreated and control cows was significant, $P<0.05$.

organism on culture $(14 / 56 ; 25.0 \%)$ than cases that did not yield coliforms $(0 / 48 ; 0.0 \% ; P<0.001)$. Additionally, cases that yielded a Klebsiella on culture were more likely to have a non-survival outcome (7/12, 58.3\%; $P$ $=0.035)$ than cases yielding $E$. coli $(11 / 44,25 \%)$. Thus, when analyzed for cases that yielded coliform organisms only, the proportion of nonsurvival cows was significantly lower for cows treated with ceftiofur $(4 / 29$, $13.8 \%)$ than untreated cows $(10 / 27,37.0 \% ; P<0.05$; Table 2).

\section{DISCUSSION}

Intramuscular administration of ceftiofur did not affect the outcome of severe clinical mastitis when all cases were included in the analysis. However, based on previous research (Cebra et al., 1996; Wenz et al., 1998) that suggested deleterious clinical outcome with bacteremia, the rationale behind this study was to determine if ceftiofur would be beneficial for severe coliform mastitis. Although about half of the severe mastitis cases in our study were caused by coliform organisms (and possibly more if these organisms accounted for some of the no organism isolated results), those cases that yielded coliforms were almost eight times more likely to result in treatment failure or loss of the cow as compared to cases with other causative agents. This is consistent with previous reports that demonstrated that coliform organisms are more likely to cause severe clinical mastitis (Anderson et al., 1982), approximately 25\% of severe coliform cases result in the loss of the cow (Cebra et al., 1996), and there is a positive correlation between concentration of bacteria isolated in milk and subsequent severity of clinical outcome for both experimental and naturally occurring cases of coliform mastitis (Erskine et al., 1989; Lohuis et al., 1990; Wenz et al., 1998). Klebsiella sp. were particularly prone to develop into deleterious outcomes, even more so than cases caused by $E$. coli. Thus, in our study, when effects of ceftiofur therapy were determined among coliform cases alone, cows receiving ceftiofur treatment had a lower rate of death and culling. This supports previous studies that suggested systemic antibacterial therapy is beneficial to cows with coliform mastitis (Shpigel et al., 1997; Morin et al., 1998a). It is likely this effect is due to modification of the effects of bacteremia because ceftiofur does not distribute into the gland, and intramammary administration of pirlimycin in support of systemic ceftiofur therapy would probably not inhibit the growth of Gram-negative organisms within the gland. It is possible that numerous cases that yielded no organism from culture represented milder cases of coliform mastitis, which were resolved before potential effects such as bacteremia could result. Thus, therapeutic benefit would only be gained for coliform cases that potentially had a more serious outcome, as evidenced by isolation of bacteria at clinical presentation. The economic feasibility of this success would have to consider ceftiofur treatment for all severe clinical mastitis cases, including those caused by other pathogens, which are not likely to respond. Selection of treatment for coliform cases only from the population of all severe mastitis cases is difficult to do based on-farm clinical presentation (Morin et al., 1998b), as evidenced by the lack of definable trends in our study for rectal temperature, and that $46 \%$ of cases did not yield coliform organisms.

In hindsight, we should have collected MIC information for all isolates after culture. This may have presented an explanation for therapeutic failure among some of the cases treated with ceftiofur. Literature provided by the manufacturer states that plasma concentrations of active drug near $1 \mu \mathrm{g} / \mathrm{mL}$ can be sustained for $24 \mathrm{~h}$ after intramuscular injection. Data provided by the manufacturer and our experience in the Animal Health Diagnostic Laboratory at Michigan State Uni- 
versity suggests that $95 \%$ of coliform isolates have an MIC of $\leq 1.0 \mu \mathrm{g} / \mathrm{mL}$ for ceftiofur. However, we did not design the study initially to determine this relationship. Unfortunately, at the end of the study when we attempted to determine MIC for our mastitis isolates; we had sustained significant losses from extended freezing. We were able to recover 8 Klebsiella isolates; all had MIC $\leq 0.5 \mu \mathrm{g} / \mathrm{mL}$. We were only able to recover three $E$. coli isolates; two had an MIC of $\leq 0.5 \mu \mathrm{g} / \mathrm{mL}$, and a third had an $\mathrm{MIC}$ of $\leq 8.0 \mu \mathrm{g} / \mathrm{mL}$. Interestingly, this resistant isolate was isolated from a sample collected from a cow that fully recovered. Thus, our small data set supported the concept that if plasma concentrations of ceftiofur can be maintained $\geq 1.0 \mu \mathrm{g} / \mathrm{mL}$ between doses, this should be adequate to maintain effective concentrations for a vast majority of coliform isolates.

We did not record incidence of all clinical mastitis cases in the study herds, thus making it difficult to calculate the exact proportion of all clinical cases that display severe clinical signs. The high proportion of cases in this trial that occurred during mid-lactation (90 to 150 d) was unexpected. Earlier reports of clinical mastitis (Erskine et al., 1988; Hogan et al., 1989) have determined that the largest proportion of clinical cases occurs in early lactation, which may coincide with impaired neutrophil migration in the gland (Hill, et al., 1978; Preisler, et al., 2000) Our study recorded severe cases only, possibly creating a bias in results. The peak frequency of cases in our trial coincided with, or soon after, peak milk production typical for these herds. The herds in our study likely had an average production per cow higher than previous studies, but the effects of milk production on the propensity for an intramammary infection to develop into a severe clinical case are speculative.

\section{CONCLUSION}

We conclude that intramuscular administration of ceftiofur did not affect the outcome of severe clinical mastitis when all etiologic agents are included in the analysis. However, for cases caused by coliform organisms, ceftiofur therapy reduced the proportion of cases that resulted in cow death or culling. This benefit may be realized because of the amelioration of bacteremicrelated pathogenesis.

\section{REFERENCES}

Anderson, K. L., A. R. Smith, and B. K. Gustaffson. 1982. Diagnosis and treatment of acute mastitis in a large dairy herd. J. Am. Vet. Med. Assoc. 181:690-696.

Cebra, C. K., F. B. Garry, and R. P. Dinsmore. 1996. Naturally occurring acute coliform mastitis in Holstein cattle. J. Vet. Intern. Med. 10:252-257.

Erskine, R. J. 2000. Antimicrobial therapy of bovine mastitis. In Antimicrobial Therapy in Veterinary Medicine, 3rd edition, Prescott, Walker, Baggot, eds. Iowa State University Press, Ames, Iowa, pp.712-734.

Erskine, R. J., R. J. Eberhart, P. J. Grasso, and R. W. Scholz. 1989. Induction of Escherichia coli mastitis in cows fed selenium-deficient or selenium-supplemented diets. Am. J. Vet. Res. 50:2093-2099.

Erskine, R. J., R. J. Eberhart, L. J. Hutchinson, S. B. Spencer, and M. A. Campbell. 1988. Incidence and types of clinical mastitis in dairy herds with high and low somatic cell counts. J. Am. Vet. Med. Assoc. 192:761-769.

Erskine, R. J., R. C. Wilson, J. W. Tyler, K. A. McClure, and R. S. Nelson. 1995. Ceftiofur distribution in serum and milk from clinically normal cows and cows with experimental Escherichia coli-induced mastitis. Am. J. Vet. Res. 56:481-486.

Hill, A. W., A. L. Shears, and K. G. Hibbit. 1978. The pathogenesis of experimental Escherichia coli mastitis in newly calved dairy cows. Res. Vet. Sci. 25:97-101.

Hogan, J. S., K. L. Smith, K. H. Hoblet, P. S. Schoenberger, D. A. Todhunter, W. D. Hueston, D. E. Pritchard, G. L. Bowman, L. E. Heider, B. L. Brockett, and H. R. Conrad. 1989. Field survey of clinical mastitis in low somatic cell count herds. J. Dairy Sci. $72: 1547-1556$.

Lohuis, J. A. C. M., Y. H. Schukken, and J. H. M. Verheijden. 1990. Effect of severity systemic clinical signs during the acutephase of experimentally-induced Escherichia coli mastitis on milk production losses. J. Dairy Sci. 73:333.

Morin, D. E., R. D. Shanks, and G. C. McCoy. 1998a. Comparison of antibiotic administration in conjunction with supportive measures versus supportive measures alone for treatment of dairy cows with clinical mastitis. J. Am. Vet. Med. Assoc. 213:676-683.

Morin, D. E., P. D. Constable, and G. C. McCoy. 1998b. Use of clinical parameters for differentiation of gram-positive and gram-negative mastitis in dairy cows vaccinated against lipopolysaccharide core antigens. J. Am. Vet. Med. Assoc. 212:1423-1431.

National Mastitis Council (NMC). 1999. Laboratory and Field Handbook on Bovine Mastitis. NMC, Madison, WI.

Owens, W. E., Z. Y. Xiang, and C. H. Ray. 1990. Determination of milk and mammary tissue concentrations of ceftiofur after intramammry and intramuscular therapy. J. Dairy Sci. 73:3449-3456.

Preisler, M. T., P. S. D. Weber, R. J. Tempelman, R. J. Erskine, H. Hunt, and J. L. Burton. 2000. Glucocorticoid receptor downregulation in neutrophils of periparturient cows. Am. J. Vet. Res. 61:14-19.

Shpigel, N. Y., D. Levin, and M. Winkler. 1997. Efficacy of cefiquinome for treatment of cows with mastitis experimentally induced using Escherichia coli. J. Dairy Sci. 80:318-325.

Wenz, J. R., G. M. Barrington, F. B. Garry, G. M. Goodell, and R. P. Dinsmore. 1998. Characterization of naturally occurring coliform mastitis. J. Dairy Sci. 81:suppl 1:38. 